\title{
Sialyl Lewis $x$ expression in canine malignant mammary tumours: correlation with clinicopathological features and E-Cadherin
} expression

\author{
Salomé S Pinho ${ }^{1,2}$, Augusto JF Matos ${ }^{2}$, Célia Lopes ${ }^{2}$, Nuno T Marcos${ }^{1}$, \\ Júlio Carvalheira ${ }^{2}$, Celso A Reis ${ }^{1,3}$ and Fátima Gärtner*1,2
}

Address: ${ }^{1}$ Institute of Molecular Pathology and Immunology of the University of Porto (IPATIMUP), Rua Dr Roberto Frias s/n, $4200-465$ Porto, Portugal, 2Institute of Biomedical Sciences of Abel Salazar (ICBAS), University of Porto, Largo Prof. Abel Salazar, 2, 4099-003 Porto, Portugal and ${ }^{3}$ Medical Faculty, University of Porto, Alameda Prof. Hernâni Monteiro 4200-319 Porto, Portugal

Email: Salomé S Pinho - salomep@ipatimup.pt; Augusto JF Matos - ajmatos@icbas.up.pt; Célia Lopes - celiacristinalopes@gmail.com; Nuno T Marcos - nmarcos@ipatimup.pt; Júlio Carvalheira - jgc3@mail.icav.up.pt; Celso A Reis - celso.reis@ipatimup.pt;

Fátima Gärtner* - fgartner@ipatimup.pt

* Corresponding author

Published: 6 July 2007

BMC Cancer 2007, 7:124 doi:10.1186/147I-2407-7-124
Received: 2 January 2007

Accepted: 6 July 2007

This article is available from: http://www.biomedcentral.com//47/-2407/7//24

(c) 2007 Pinho et al; licensee BioMed Central Ltd.

This is an Open Access article distributed under the terms of the Creative Commons Attribution License (http://creativecommons.org/licenses/by/2.0), which permits unrestricted use, distribution, and reproduction in any medium, provided the original work is properly cited.

\begin{abstract}
Background: Sialyl Lewis $x\left(s L e^{x}\right)$ antigen is a carbohydrate antigen that is considered not only a marker for cancer but also implicated functionally in the malignant behaviour of cancer cells. Overexpression of $s \mathrm{~L}^{\mathrm{x}}$ is associated with enhanced progression and metastases of many types of cancer including those of the mammary gland. Canine mammary tumours can invade and give rise to metastases via either lymphatic or blood vessels.

E-Cadherin is specifically involved in epithelial cell-to-cell adhesion. In cancer, E-Cadherin underexpression is one of the alterations that characterizes the invasive phenotype and is considered an invasion/tumour suppressor gene. Partial or complete loss of $\mathrm{E}-\mathrm{Cadherin}$ expression correlates with poor prognosis in canine malignant mammary cancer.
\end{abstract}

The aim of this study was to analyse the sLex expression in canine malignant mammary tumours and to evaluate if the presence of sLex correlates with the expression of E-Cadherin and with clinicopathological features.

Methods: Fifty-three cases of canine mammary carcinomas were analysed immunohistochemically using monoclonal antibodies against $s \mathrm{e}^{\times}(\mathrm{IgM})$ and $\mathrm{E}-\mathrm{Cadherin}(\mathrm{IgG})$. The clinicopathological data were then assessed to determine whether there was a correlation with $s \mathrm{Le}^{\mathrm{x}}$ tumour expression. Double labelled immunofluorescence staining was performed to analyse the combined expression of $\mathrm{sLe}^{\mathrm{x}}$ and $\mathrm{E}$-Cadherin.

Results: sLex expression was consistently demonstrated in all cases of canine mammary carcinomas with different levels of expression. We found a significant relationship between the levels of sLex expression and the presence of lymph node metastases. We also demonstrated that when $\mathrm{E}$-Cadherin expression was increased sLex was reduced and vice-versa. The combined analysis of both adhesion molecules revealed an inverse relationship.

Conclusion: In the present study we demonstrate the importance of sLex in the malignant phenotype of canine malignant mammary tumours. Our results support the use of sLex as a prognostic tumour marker in canine mammary carcinomas. Furthermore, we showed that $\mathrm{SL}^{\mathrm{x}}$ and $\mathrm{E}$-Cadherin expression were inversely correlated. Future studies are warranted to clarify the molecular mechanism underlying the relation between sLex and E-Cadherin in canine mammary carcinoma cells which represents an important comparative model to woman breast cancer. 


\section{Background}

Mammary tumours are the most common tumours in intact female dogs and approximately $40 \%$ to $50 \%$ of these tumours are malignant [1]. All malignant canine mammary tumours have the potential to metastasise. In general canine malignant tumours metastasise via the lymphatics to the regional lymph nodes or hematogenously to the lungs that represent the most common site of distant metastases. [1-3]

Malignant transformation is associated with abnormal glycosylation, resulting in expression of altered carbohydrate determinants, such as the Sialyl Lewis $\mathrm{x}\left(\mathrm{sLe}^{\mathrm{x}}\right)$ antigen. Altered cell surface glycosylation is a prominent feature of malignant tumour cells and define their invasive and/or metastatic properties in general [4-12].

Tumour metastasis is a multistep process requiring detachment of malignant cells from the primary tumour, invasion of blood or lymph vessels, interaction with endothelium, extravasation at distant sites and formation of new tumour foci $[9,12,13]$. It is generally accepted that every step of the metastatic cascade is dependent on specific adhesive interactions of cancer cells with other cells and components of the extracellular matrix. These interactions are mediated by different families of adhesion molecules including cadherins, integrins, members of the immunoglobulin superfamily, and selectins and their carbohydrate ligands - Sialyl Lewis a $\left(s L e^{a}\right)$ and sLe $^{\mathrm{x}}$ $[9,13,14]$.

sLe $^{\mathrm{x}}$ is a tetrasaccharide (NeuAc $\alpha 2 \rightarrow 3 \mathrm{Gal} \beta 1 \rightarrow 4$ [Fuc $\alpha 1$ $\rightarrow 3$ ]GlcNAc $\beta 1 \rightarrow \mathrm{R}$ ) that is particularly relevant from a biological standpoint. It is involved in selectin-mediated adhesion of cancer cells to vascular endothelium and this determinant is thought to be closely associated with hematogenous metastases of cancer [12-17]

In humans, the expression of sLe $\mathrm{e}^{\mathrm{x}}$ is significantly increased in carcinoma cells $[4,7,18]$. Many clinical studies have shown an association between the expression of $\operatorname{sLe}^{\mathrm{x}}$ on tumours and enhanced tumour progression and metastasis $[7,19]$. In woman breast carcinoma the presence of sLe ${ }^{x}$ was also correlated with poor prognosis [20,21]. In fact, the presence of sLe $e^{\mathrm{x}}$ has been used as a prognostic tumour marker in various types of human cancer $[7,19]$, e.g. lung [22], bladder [8], breast [20,21,23], prostate [24], colon [25] and gastric [26-28] carcinoma. Little is known about the expression of sLe ${ }^{\mathrm{x}}$ in canine tumours. To the best of our knowledge only the study of Nakagawa et al describe the expression of sLe ${ }^{\mathrm{x}}$ in canine and feline mammary gland tumours [29], but no significant correlation between the expression of $\mathrm{sLe}^{\mathrm{x}}$ and prognosis has been described in canine or feline tumours.
sLe ${ }^{\mathrm{x}}$ and E-cadherin are two adhesion molecules that seem to be involved in malignant progression with opposite roles [31]. Alpaugh et al have described a cooperative role between E-cadherin and $s \mathrm{Le}^{\mathrm{x}}$ in the passive dissemination of tumour emboli and in the genesis of the lymphovascular embolus of woman's Inflammatory Breast Carcinoma [30-32].

Recently, Jeschke et al identified a negative correlation between Sialyl Lewis antigens and E-cadherin expression in woman breast cancer and their lymph node metastases [23]. This combined analysis of tumour antigens involved in adhesion of breast cancer cells has never been described in canine mammary tumours, which constitutes an important comparative model for woman breast cancer.

The purpose of the present study is to analyse, by immunohistochemical staining methods, the expression of the carbohydrate $\mathrm{sLe}^{\mathrm{x}}$ in canine malignant mammary tumours and to evaluate the relationship between sLe $e^{x}$ expression and tumour clinicopathological features. The relation between the expression of the molecules sLex and E-Cadherin [33] in canine malignant mammary tumours was also investigated.

\section{Methods \\ Tissue specimens}

Fifty-three malignant mammary tumours and 102 local and regional lymph nodes were surgically removed from 35 female dogs aged from 3 to 16 (mean, 9.9 years), of various pure or mixed breeds. The specimens were fixed in $10 \%$ neutral buffered formalin. After dehydration and paraffin wax embedment, sections of $4 \mu \mathrm{m}$ were cut from each representative paraffin blocks for staining with haematoxylin and eosin (HE) and for sLe ${ }^{\mathrm{x}}$ and E-cadherin immunohistochemistry (IHC).

Lymph nodes were classified according to the presence of cancer cells (positive or negative), using HE and cytokeratin IHC methods [33].

\section{Histological examination of the tumours}

Tumours, including benign proliferative lesions found in the vicinity of the tumours, were classified independently by two observers from HE-stained sections on the basis of the diagnostic criteria of the World Health Organization classification of tumours in domestic animals [34].

The presence of intra-tumoral necrosis was registered for each case and evaluation and classification of the mode of tumour growth was assessed as previously described [33].

\section{Follow-up data}

All animals were clinically evaluated every 3 months (by physical examination, thoracic radiography and abdomi- 
nal ultrasound) for the presence of distant metastases during a follow-up period of 2 years after surgery. All dogs were followed until death or until the end of the observation period. In all dogs that died with suspected distant metastases, complete necropsies were performed and histological confirmation was obtained.

\section{Immunohistochemistry}

Canine mammary cancer tissues, which had been resected by the curative operation were routinely processed and used for immunostaining of sLe ${ }^{\mathrm{x}}$ and E-cadherin.

Immunostaining was performed by the modified avidinbiotin-peroxidase complex (ABC) method [35]. Two distinct monoclonal antibodies (mAbs) were used: the mAb FH6 generated against sLex epitope [36] and the monoclonal mouse anti-human E-cadherin antibody (clone 4A2C7, Zymed, S.Francisco, California, USA) [33].

Tumour sections ( 4 um thick) were deparaffinized in xylene, dehydrated through graded concentrations of ethanol and washed with distilled water. Sections were then treated with Citrate buffer (sodium citrate antigen retrieval solution; $10 \mathrm{mM}$ citric acid, $\mathrm{pH}=6$ ) for $20 \mathrm{~min}$ utes in a microwave oven at $600 \mathrm{~W}$. The slides were cooled for 10 minutes at room temperature and rinsed twice in Phosphate buffered saline (PBS) for 5 minutes. Endogenous peroxidase activity was blocked by treating the section with hydrogen peroxide $3 \%$ in methanol for $10 \mathrm{~min}$. After washing the slides in PBS, non-specific staining was eliminated by incubating the sections with normal rabbit serum (Dako) diluted at 1:5 in PBS containing bovine serum albumin (BSA) 10\%, in a humid chamber for 20 $\mathrm{min}$ at room temperature. Excess normal serum was removed and replaced by the anti-sLe ${ }^{\mathrm{x}} \mathrm{mAb}$ FH6 diluted at 1:5. After overnight incubation ( $\cong 18$ hours) at $4{ }^{\circ} \mathrm{C}$, slides were washed with PBS and incubated for 30 min with a 1:200 dilution of biotin-labelled rabbit anti-mouse secondary antibody (Dako). Sections were then washed with PBS and incubated for $30 \mathrm{~min}$ with avidin-biotin complex (Dako) diluted at 1:100. This was followed by staining the sections for 5 to 7 minutes with $0.05 \%$ 3,3 diaminobenzidinetetrahydrochloride (DAB) freshly prepared in $0.05 \mathrm{M}$ Tris/hydroxymethylaminomethane buffer, $\mathrm{pH}$ 7.6, containing $0.1 \%$ hydrogen peroxide. Finally, sections were lightly counterstained with haematoxylin, dehydrated, and mounted.

Dilution of primary antibody, biotin-labelled secondary antibody, and avidin-biotin complex were made with PBS containing 5\% BSA.

All series included, as positive control sections of a human mixed gastric carcinoma previously shown to display prominent expression of sLex .
Negative controls were performed by substitution of the primary antibody with immunoglobulins of the same subclass and concentration as the monoclonal antibody.

\section{Scoring of immunostaining and statistical analysis}

The degree of mAb FH6 reactivity with individual tissue sections was scored by percentage of stained carcinoma cells in the section by three authors (S.S.P., C.A.R., F.G.) without knowing patients outcome and clinicopathological features of the case. In the event of disagreement, slides were reviewed by the observers, and a consensus was obtained.

Expression of sLe ${ }^{\mathrm{x}}$ and E-cadherin [33] in canine mammary carcinomas were classified in the following manner: negative, no immunoreactivity or immunostaining in very rare cells; less than $25 \%$ of cancer cells stained; $25-50 \%$, well defined areas with positive cells; $\underline{50-75 \%}$ of cancer cells stained; and more than $75 \%$ stained cells. Scoring of immunoreactivity was evaluated irrespectively of localization of positive cells and intensity of the staining.

For statistical analysis the expression of $\mathrm{sLe}^{\mathrm{x}}$ was regrouped in two percentual categories ( $<25 \%$ and $\geq 25 \%$ ) in order to increase the number of cases in each category and in this manner improve the statistical power of the tests.

The statistical relationship among variables was analysed using tables of frequencies and their significance tested by the Fisher's exact test [37]. P values less than 0.05 were considered a significant association.

\section{Double-labelling Immunofluorescence}

For simultaneous visualization of sLex and E-cadherin on the same tissue section, double-label immunofluorescence was performed. We chose the following representative tissue sections: sections with $<25 \%$ sLe $^{\mathrm{x}}$ and $>75 \%$ ECadherin expression; sections with $>75 \%$ sLe $^{\mathrm{x}}$ and $<25 \%$ E-Cadherin expression and sections with the same percentage of positive cells for both mAbs.

Paraffin sections were dewaxed, rehydrated and then treated with Extran (Merck, Frankfurt, Germany) 0.05\% in distilled water for $10 \mathrm{~min}$ in a microwave oven at $750 \mathrm{~W}$. After cooled for $20 \mathrm{~min}$ at room temperature, slides were rinsed twice in Phosphate-buffered saline (PBS) and then incubated for $20 \mathrm{~min}$ in a humid chamber with rabbit non-immune serum at a dilution 1:5 in PBS containing bovine serum albumin (BSA) $10 \%$. Sections were incubated with the first primary $\mathrm{mAb}$, anti-human E-Cadherin (clone 36, BD Biosciences Pharmigen, diluted 1:100 in PBS), overnight at $4{ }^{\circ} \mathrm{C}$. After washing twice for $5 \mathrm{~min}$ in PBS, sections were incubated with FITC-conjugated rabbit anti-mouse immunoglobulin (code F261; Dako, Glos- 
trup, Denmark; diluted 1:100 in PBS). Sections were washed two times for 5 min in PBS and blocked with nonimmune goat serum diluted 1:5 in PBS containing BSA $10 \%$. Sections were then incubated with mAb FH6 (mouse IgM) diluted at 1:5, overnight at $4{ }^{\circ} \mathrm{C}$. Sections were washed two times for 5 min with PBS and incubated with Texas red-conjugated goat anti-mouse IgM (Jackson Immunoresearch) diluted 1:50 in PBS. Sections were washed as before and nuclei were counterstained with 4'6-Diamidino-2-phenylindole (DAPI, Sigma) for $15 \mathrm{~min}$ in the dark, diluted at 1:100 in PBS. Sections were washed two times for 5 min in PBS and mounted with Vectashield (Vector Laboratories, Burlingame, USA).

Dilutions of primary antibodies, secondary antibodies, and DAPI were made with PBS containing 5\% BSA.

\section{Microscopy and image processing}

Immunostained slides were examined under a fluorescence microscope (Leica DMIRE2) equipped with appropriate filters. Separate images for DAPI, Texas-Red and FITC staining were captured digitally at $\times 200$ and $\times 400$ magnification. The red (for Texas-Red), blue (for DAPI), and green (for FITC) components were merged and composite images were imported into Adobe Photoshop 7.0

\section{Results \\ Clinical and pathological features of mammary carcinoma patients}

All dogs that were included in this study were female. The mean age at surgery was 9.9 years old (range: 3-16 years old). Histological diagnosis of canine mammary carcinomas consisted of 2 in situ carcinomas, 13 complex carcinomas, 13 tubulopappilary carcinomas, 9 solid carcinomas, 1 spindle cell carcinoma, 3 mucinous carcinomas, 10 carcinosarcomas and 2 carcinomas in benign tumour.

The mode of tumour growth was assessed in all of 53 tumours. Invasive tumours were more prevalent (28 cases, $52.8 \%$ ) followed by expansive tumours (17 cases, $32.1 \%$ ) and tumours with vessel invasion (8 cases, 15.1\%).

Lymph node metastases were evaluated in 50 tumours (in 3 cases the regional lymph nodes were not submitted). The majority of the cases did not show lymph node metastases $(39,78.0 \%)$ whereas eleven patients $(22.0 \%)$ revealed metastases in regional lymph nodes. The majority of the cases that showed lymph node metastases were classified as carcinosarcomas (6 out of 11). The others were classified as complex carcinoma, tubulopapillary carcinoma and solid carcinoma. From the eleven cases that revealed nodal metastases, 4 patients revealed in addition, distant metastases. Seven patients with lymph node metastases died (in 4 animals was performed eutha- nasia because of the tumour and 3 animals died of other causes).

The presence of intra-tumoral necrosis was observed in thirty tumours (56.6\%), whereas 23 (43.4\%) tumours did not show this feature.

Of the 35 dogs that were included in this study, 33 completed the follow-up period and ten dogs (30.3\%) developed distant metastases. From the 17 dogs that died at the end of the follow-up period, 52,9\% died because of the mammary carcinoma and $47,0 \%$ died from other causes.

\section{Expression of Sialyl Lewis $x$ in canine mammary carcinomas}

All of the carcinomas studied by immunohistochemistry showed expression of sLe $e^{\mathrm{x}}$ antigen (Figure 1). Thirty two $(60.4 \%)$ were found to express sLe ${ }^{\mathrm{x}}$ in less than $25 \%$ of the cells, whereas $21(39.6 \%)$ showed sLex expression in more than $25 \%$ of the cells. This distribution of sLe $e^{\mathrm{x}}$ expression include the early stage cases of canine mammary carcinomas such as in situ carcinoma and carcinoma in benign tumour (Table 1). The staining was observed in the cytoplasm and/or in the cell membrane of epithelial cells. In tumour areas with cellular squamous differentiation, sLe ${ }^{\mathrm{x}}$ was always expressed (Figure 2). In all cases, the adjacent normal mammary gland tissue and the adjacent benign proliferative lesions were evaluated and they did not showed expression of sLe $e^{x}$ It was analysed a total of 43 adjacent benign proliferative lesions ( 6 simple adenomas, 8 epithelioses and the others were hyperplasias in general). In proliferative lesions sLe ${ }^{\mathrm{x}}$ was expressed only in mammary gland secretion.

\section{Relationship between Sialyl Lewis $x$ expression and clinicopathological features}

Table 1 summarizes the expression of sLe $\mathrm{e}^{\mathrm{x}}$ according to clinicopathological features.

No significant relationship was found between the expression of sLe ${ }^{x}$ antigen and the different histological types of canine mammary carcinoma according to the World Health Organization classification of tumours in domestic animals [34].

Similarly, no significant relationship was observed between sLex expression and the growth pattern of mammary carcinomas.

A total of $63.6 \%$ of tumours with lymph node metastases showed significantly higher sLex expression $(\geq 25 \%)$, whereas most $(74.4 \%)$ of the tumours without lymph node metastasis showed underexpression $(<25 \%)$ of $s L e^{x}$ $(\mathrm{p}=0.034)$. 


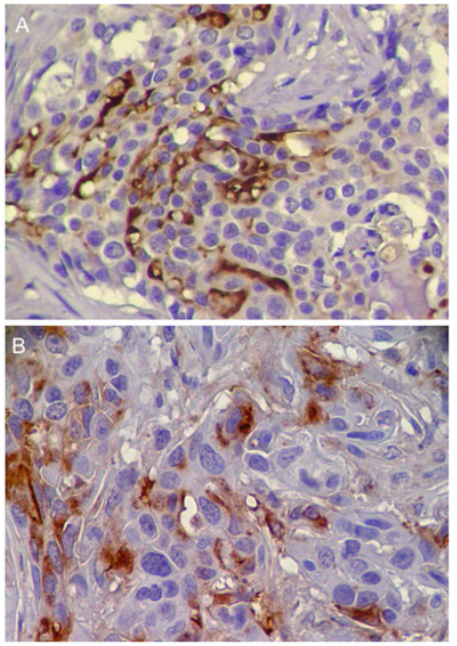

Figure I

Immunohistochemical study of the expression of Sialyl Lewis $x$ in canine malignant mammary tumours. A. Solid carcinoma; $>75 \%$ of sLex expression; $\times 400$ B. Carcinosarcoma; $25-50 \%$ of cells stained; $\times 400$.
Although this association did not reach a statistical significance, we observed that tumours without necrosis showed less sLe ${ }^{\mathrm{x}}$ expression than tumours with necrosis ( $\mathrm{p}$ $=0.07$ ).

No significant relationship was found between the expression of sLe ${ }^{\mathrm{x}}$ antigen and distant metastases.

\section{Relationship between Sialyl Lewis $x$ and E-cadherin expression}

The analysis of expression of sLe ${ }^{\mathrm{x}}$ and E-cadherin disclosed an inverse correlation among the two molecules, higher sLe ${ }^{\mathrm{x}}$ expression was accompanied with lower Ecadherin expression and vice-versa (Figure 3). When mammary carcinomas show underexpression of E-cadherin $(<25 \%)$, all of them simultaneously revealed a higher sLe $e^{\mathrm{x}}$ expression $(\geq 25 \%)$. On the other hand when tumour samples showed overexpression of E-cadherin (>75\%) the majority of them (93.1\%) simultaneously revealed less than $50 \%$ of sLe ${ }^{x}$ expression. In summary, we found a significant relationship $(\mathrm{p}=0.013)$ between $\mathrm{sLe}^{\mathrm{x}}$ and E-cadherin expression in canine malignant mammary tumours (Table 2).

Table I: Relationship between Sialyl Lewis $\mathrm{x}$ expression and clinicopathological features in canine malignant mammary tumours.

\begin{tabular}{|c|c|c|c|c|}
\hline \multirow[b]{2}{*}{ Clinical Features } & \multirow[b]{2}{*}{ Number of cases(\%) } & \multicolumn{2}{|c|}{ Sialyl Lewis $x$ expression } & \multirow[b]{2}{*}{$P$ value } \\
\hline & & $<25 \%$ & $\geq \mathbf{2 5} \%$ & \\
\hline Histological type $(n=53)$ & & & & $N S(0,075)$ \\
\hline In situ carcinoma & $2(3.8 \%)$ & I (50.0\%) & I (50.0\%) & \\
\hline Complex carcinoma & $13(24.5 \%)$ & $12(92.3 \%)$ & I (7.7\%) & \\
\hline Tubulopapillary carcinoma & $13(24.5 \%)$ & $7(53.8 \%)$ & $6(46.2 \%)$ & \\
\hline Solid carcinoma & $9(17.0 \%)$ & $5(55.6 \%)$ & $4(44.4 \%)$ & \\
\hline Spindle cell carcinoma & I (I.9\%) & $\mathrm{I}(100.0 \%)$ & $0(0.0 \%)$ & \\
\hline Mucinous carcinoma & $3(5.7 \%)$ & I (33.3\%) & $2(66.7 \%)$ & \\
\hline Carcinosarcoma & $10(18.9 \%)$ & $4(40.0 \%)$ & $6(60.0 \%)$ & \\
\hline Carcinoma in benign tumour & $2(3.8 \%)$ & I (50.0\%) & I (50.0\%) & \\
\hline Mode of Growth $(n=53)$ & & & & $N S(0,27)$ \\
\hline Expansive & $17(32.1 \%)$ & $13(76.5 \%)$ & $4(23.5 \%)$ & \\
\hline Invasive & $28(52.8 \%)$ & $15(53.6 \%)$ & $13(46.4 \%)$ & \\
\hline Vessel invasion & $8(15.1 \%)$ & $4(50.0 \%)$ & $4(50.0 \%)$ & \\
\hline Lymph node metastases $(n=50)^{*}$ & & & & 0.034 \\
\hline No & $39(78.0 \%)$ & $29(74.4 \%)$ & $10(25.6 \%)$ & \\
\hline Yes & II (22.0\%) & $4(36.4 \%)$ & 7 (63.6\%) & \\
\hline Necrosis $(n=53)$ & & & & $N S(0,078)$ \\
\hline Absent & $23(43.4 \%)$ & 17 (73.9\%) & $6(26.1 \%)$ & \\
\hline Present & $30(56.6 \%)$ & $15(50.0 \%)$ & $15(50.0 \%)$ & \\
\hline Distant Metastasis $(n=33)$ & & & & $N S(0,24)$ \\
\hline No & $23(69.7 \%)$ & $17(73.9 \%)$ & $6(26.1 \%)$ & \\
\hline Yes & $10(30.3 \%)$ & $5(50.0 \%)$ & $5(50.0 \%)$ & \\
\hline
\end{tabular}

* No lymph nodes were submitted with 3 tumours NS - Not significant $(P>0.05)$ 


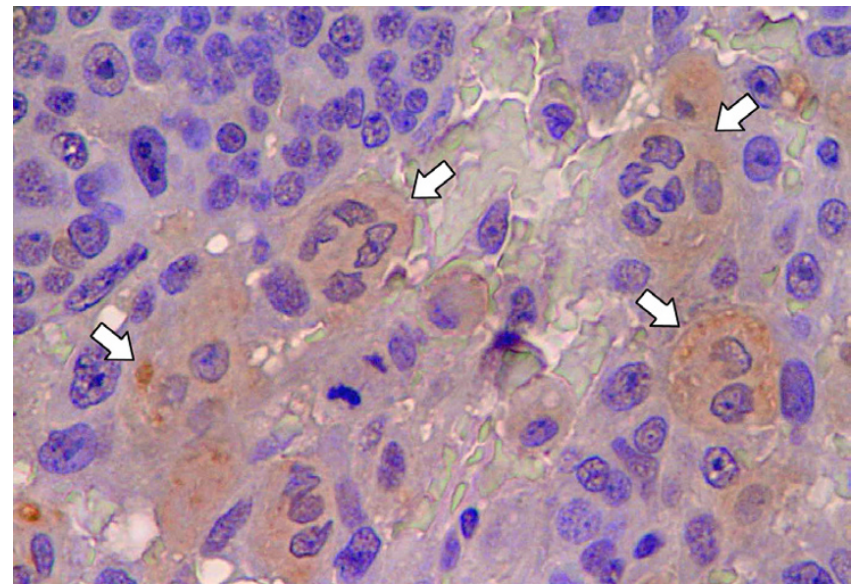

Figure 2

Immunohistochemical expression of Sialyl Lewis $\mathrm{x}$ in squamous metaplasia. All cells that exhibit squamous metaplasia (arrows) are positive for Sialyl Lewis x. $\times 400$

Simultaneous expression of sLe ${ }^{\mathrm{x}}$ and E-cadherin was analysed using double-label immunofluorescence method (Figure 4), demonstrating the absence of overlapping between the two molecules (Figure 4). Based on these results, it seems that, when cells express sLe ${ }^{x}$ they do not express E-cadherin, and on the other hand when they are positive for E-cadherin they are negative for sLe ${ }^{\mathrm{x}}$.

\section{Discussion}

Malignant transformation of tumour cells is associated with abnormal glycosylation, resulting in expression of altered carbohydrate determinants including the expression of sLe ${ }^{\mathrm{x}}$ and sLe $\mathrm{s}^{\mathrm{a}}$ antigens $[4,9,12]$. These carbohydrate antigens have been shown to be useful tumour markers in carcinomas of different organs $[4,9,12]$. The biosynthesis of these oligosaccharides are usually increased and altered during the acquisition of the malignant phenotype and tumour progression $[5,12]$. Some studies refer that aberrant glycosylation is a result of initial oncogenic transformation, as well as a key event in induction of invasion and metastases [10,12].

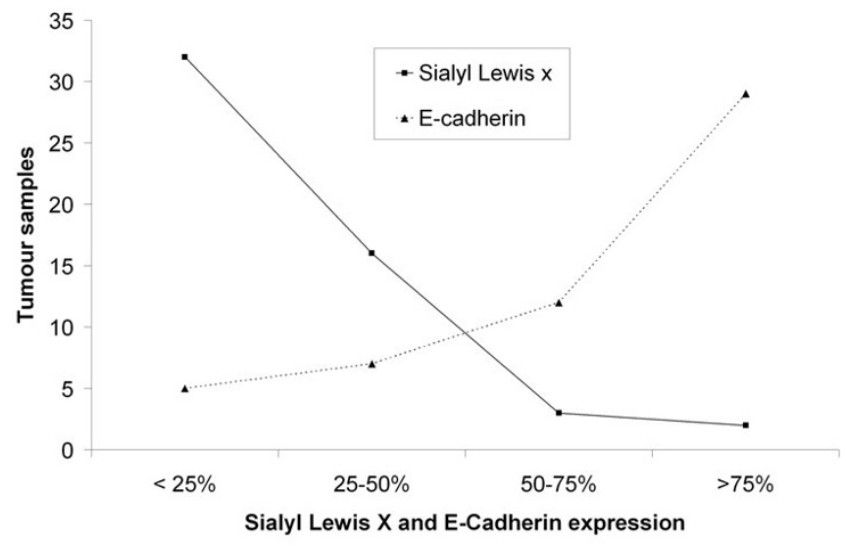

\section{Figure 3}

Relation between Sialyl Lewis $x$ and E-cadherin expression. The figure illustrates the negative correlation between $s L e^{x}$ and $\mathrm{E}-$ Cadherin expression in canine malignant mammary tumours. When expression of $\mathrm{E}$-cadherin increase, the expression of $s L e^{x}$ decrease and vice-versa.

Most human carcinomas show changes within cell surface carbohydrates compared to their normal counterparts $[4,12]$.

sLex, present on the surface of tumour cells has been found to serve as ligands for endothelial E-selectin and was shown to play a major role in the process of adhesion of cancer cells to the endothelium [38]. sLe $e^{\mathrm{x}}$ not only is a marker for cancer but also is functionally implicated in the malignant behaviour of cancer cells [4,12-14]. E-selectin, one of the selectin family member is expressed on the vascular endothelial cells and adheres to a carbohydrate ligand, sLe $e^{x}[15,16]$. Binding of sLex, present on the cell membrane of neutrophil granulocytes, to E-selectin, expressed on activated endothelial cells, was shown to initiate neutrophil extravasation and migration into tissues [15]. It has been hypothesized that the E-selectin/sLex interaction can mediate the sequence of adhesion of tumour cells to endothelium and their subsequent extravasation in a process that mimics the above process

Table 2: Relationship between Sialyl Lewis $x$ and E-cadherin expression in canine malignant mammary tumours.

\begin{tabular}{lccc}
\hline & & \multicolumn{2}{c}{ Sialyl Lewis x expression } \\
\cline { 3 - 4 } E-Cadherin expression & Number of cases (\%) & $<25 \%$ & $\geq 25 \%$ \\
\hline$<25 \%$ & $5(9.4 \%)$ & $0(0.0 \%)$ & \multicolumn{2}{c}{$\boldsymbol{P}$ value } \\
$25-50 \%$ & $7(13.2 \%)$ & $6(85.7 \%)$ & $1(14.3 \%)$ \\
$50-75 \%$ & $12(22.6 \%)$ & $9(75.0 \%)$ & $3(25.0 \%)$ \\
$>75 \%$ & $29(54.7 \%)$ & $17(58.6 \%)$ & $12(41.4 \%)$ \\
\hline
\end{tabular}



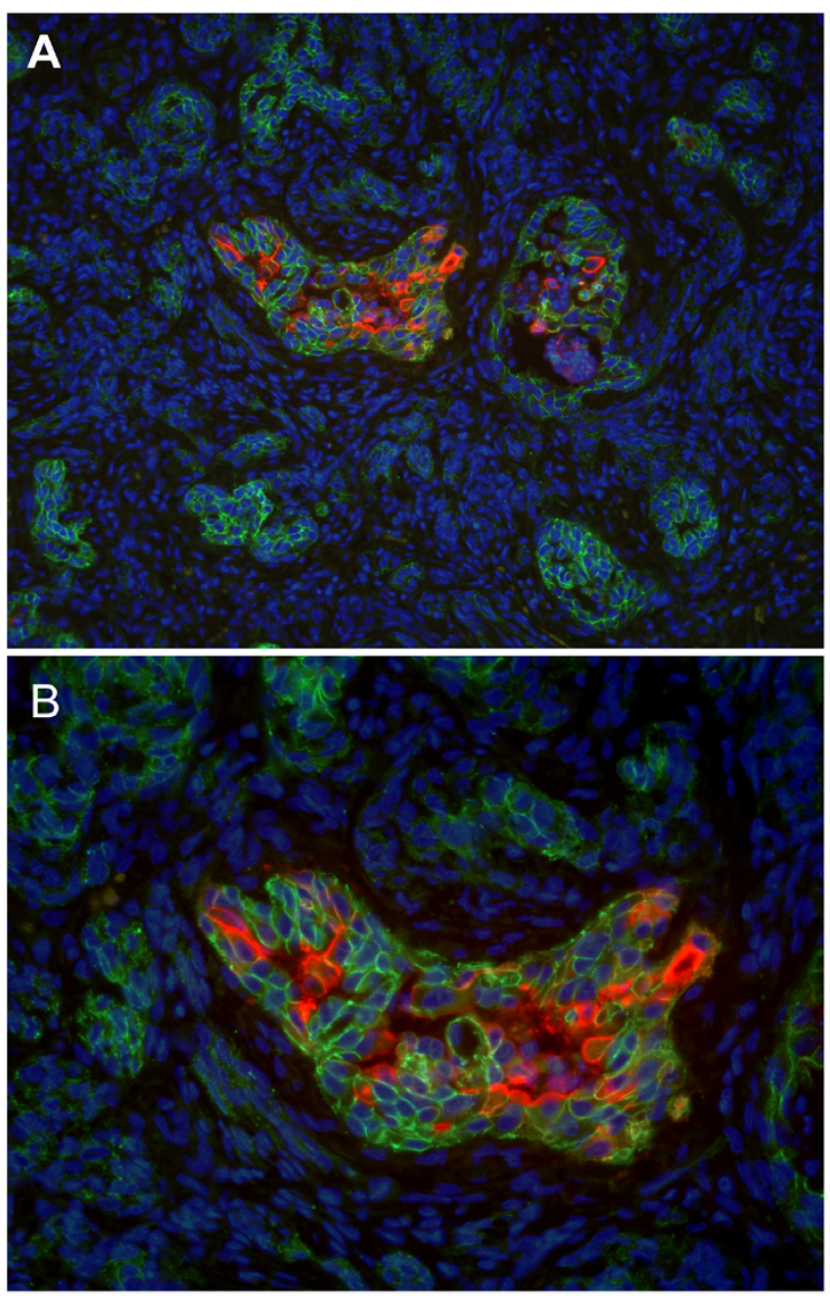

Figure 4

Double-label immunofluorescence of canine malignant mammary tumour (Complex carcinoma). A Cells that are positive for Sialyl Lewis $x$ (red) are negative for $\mathrm{E}$-cadherin (green) and vice-versa. $\times 200 \mathrm{~B}-$ Absence of coexpression of $\mathrm{sLe} \mathrm{e}^{\mathrm{x}}$ and $\mathrm{E}$-cadherin in the same cells. $\times 400$

of inflammation $[15,17]$. The sLe $e^{\mathrm{x}}$ antigen is expressed by various human carcinomas such as: gastric carcinoma [26], colorectal carcinoma [25], lung cancer [22], prostate carcinoma [24], bladder carcinoma [8], oral [39], head\&neck squamous cell carcinoma [40] and breast cancer $[11,20,23]$. The amounts of sLe ${ }^{\mathrm{x}}$ expression are closely associated with progression and with poor prognosis in those cancers.

In canine cancers, Nakagawa et al has described the expression of sLe ${ }^{\mathrm{x}}$ in canine and feline mammary gland tumours. However no association with clinicopathological features and prognosis was observed $[29,41]$.
The present study demonstrates that in malignant canine mammary tumours the malignant transformation of the mammary gland is accompanied by expression of sLe $e^{\mathrm{x}}$. These results are in agreement with previous observations showing that in squamous metaplasia, used as criteria of malignancy in canine mammary cancer [42-44], there is a strong expression of sLe $e^{\mathrm{x} a n t i g e n . ~ T h e s e ~ o b s e r v a t i o n s ~ s u p-~}$ port the use of $s e^{\mathrm{x}}$ as a prognostic tumour marker in canine mammary carcinomas.

In this study, we found no significant relationship between sLe $e^{\mathrm{x}}$ expression and the histological type of the tumours, classified according to World Health Organization classification. This result is in agreement with the results described by Nakagawa et al in canine and feline mammary gland tumours [29]. Similarly, in woman breast cancer, Nakagoe et al did not find an association between sLex expression and histological type of the carcinoma [20].

Previous studies have shown that, in woman breast cancer, tumour necrosis is associated with poorer survival [45-47] and higher recurrence rates [46]. In canine mammary tumours, the presence of large areas of necrosis within the tumour mass could be used as criteria for a diagnosis of malignancy [44]. In spite of no association between sLex expression and tumour necrosis we observed that some tumours with necrosis showed high amounts of sLe $^{\mathrm{x}}$ expression.

It is clear that the expression of sLex in tumours is a marker of the invasive and/or metastatic properties of the tumours $[4,11]$. In addition, it has been shown that sLe ${ }^{x}$ promotes binding of tumour cells at an invasion focus to endothelial cells through E-Selectin [11]. Many clinical studies show a clear association between the expression of sLe $^{\mathrm{x}}$ and tumours with enhanced progression and metastases [19]. In woman breast cancer, it was reported that the expression of $\mathrm{sLe}^{\mathrm{x}}$ antigen in tumour cells was associated with poorer prognosis [20]. Matsuura et al demonstrated that the level of sLe ${ }^{\mathrm{x}}$ was elevated in the sera of patients with metastatic breast cancers [21]. Still in woman breast cancer, Jeschke et al reports that overexpression of sLe $^{\mathrm{x}}$ was associated with poorer prognosis and malignant relapse [23].

To date, the expression of sLex in canine malignant mammary tumours, was not correlated neither with clinicopathological features, neither with prognoses [29].

In the present study we found a significant correlation between sLe $e^{\mathrm{x}}$ expression and lymph node metastases. To the best of our knowledge, this is the first study to show such a relationship in canine malignant mammary tumours. These observations may suggest that sLe ${ }^{\mathrm{x}}$ expres- 
sion may also play a role in the process of local lymphatic invasion and metastization [38]. On the other hand, we did not observe an association between sLe ${ }^{\mathrm{x}}$ expression and the development of distant metastases. This observation may suggest that in canine mammary tumours sLe ${ }^{\mathrm{x}}$ does not contribute to haematogenous metastasis. However we could not rule out that the absence of association of sLe ${ }^{\mathrm{x}}$ and haematogenous metastasis stems from the small number of cases studied for this clinicopathological feature.

These combined results from the relation between sLe ${ }^{\mathrm{x}}$ expression and the clinicopathological features allow us to conclude that the sLex carbohydrate structure contributes for the malignant phenotype and tumour progression of canine malignant mammary tumours.

Tumour cell dissemination and development of metastases is a multistep process involving complex interaction between cancer cells, extracellular matrix, the vascular system, the immune system and the target organs [48]. Adhesion molecules are contributory factors toward metastatic activity. Adhesion can be divided into reduced adhesion of tumour cell, tumour cell interaction and increased adhesion of floating tumour cells to vascular endothelial cells [48]. Recently we and other authors have described that the loss of E-Cadherin expression may have prognostic value in canine malignant mammary tumours $[33,49]$. In the present study, our results also showed that increasing expression of sLe ${ }^{\mathrm{x}}$ correlates with lymph node metastases in canine mammary carcinomas. To address a possible cooperative role between these two molecules involved in cell adhesion, sLe ${ }^{\mathrm{x}}$ and E-cadherin, we have compared their expression in canine malignant mammary tumours. Our results showed an inverse relationship between sLe ${ }^{\mathrm{x}}$ and E-cadherin expression. Cases expressing sLe $^{\mathrm{x}}$ showed decrease E-Cadherin expression and viceversa. Similarly, we could observe in doubled labelled immunofluorescence images, that cells that expressed sLe $e^{\mathrm{x}}$ were negative for E-cadherin and vice-versa. This observation is the first indication of a significant relationship between sLe ${ }^{\mathrm{x}}$ and E-cadherin expression in canine malignant mammary tumours. Based on our results it seems that the expression of sLe ${ }^{\mathrm{x}}$ and/or E-cadherin on the same tumour cell could be regulated by an internal mechanism of the cell. In a previous study in a model of woman Inflammatory Breast Carcinoma (IBC), Alpaugh et al have described a cooperative role of E-cadherin overexpression and sLe ${ }^{\mathrm{x}}$ underexpression in the genesis of the lymphovascular embolus of IBC $[30,31]$. These results showed that both types of adhesion molecules might play opposing roles within the same tumour cell model. Furthermore, Jeschke et al have also shown, in breast cancer, a negative correlation between the expression of Sialyl Lewis anti- gens and E-cadherin as the risk of breast cancer metastasis progresses [23].

Our findings, in canine mammary carcinomas, supports the generally accepted dogma that metastatic propensity is an active biologic process that includes the decrease of tumour cells adhesion at the primary tumour site (E-cadherin down-regulation) which is thought to be accompanied by higher mobility and invasiveness [50] contributing to the process of local lymphatic invasion and metastization (sLe ${ }^{\mathrm{x}}$ overexpression).

\section{Conclusion}

Our results demonstrate the importance of sLe $e^{\mathrm{x}}$ in malignant phenotype of canine mammary carcinoma and support the use of sLex as a prognostic tumour marker in canine malignant mammary gland tumours.

The significant relation between sLe ${ }^{\mathrm{x}}$ and lymph node metastases allow us to conclude that sLe ${ }^{\mathrm{x}}$ can be used as prognostic factor in canine malignant mammary tumours.

There is an inverse relationship between the expression of the adhesion molecules sLe ${ }^{\mathrm{x}}$ and E-cadherin, in canine mammary carcinomas.

The present results warrants further investigation addressing the clarification of the molecular mechanism determining this inverse correlation between $\mathrm{sLe}^{\mathrm{x}}$ and Ecadherin as well as the investigation of the mechanisms by which sLex interferes with homotypic cellular adhesion mediated by E-cadherin in canine malignant mammary tumours, as a comparative model to woman breast cancer.

\section{Abbreviations}

sLe $^{\mathrm{x}}=$ Sialyl Lewis $\mathrm{x}$; sLe $\mathrm{e}^{\mathrm{a}}=$ Sialyl Lewis a; HE = Haematoxylin and eosin; IHC = Immunohistochemistry; $\mathrm{ABC}=$ Avidin-biotin-peroxidase-complex; $\mathrm{mAbs}=$ Monoclonal antibodies; $\mathrm{PBS}=$ Phosphate buffered saline; $\mathrm{BSA}=$ Bovine serum albumin; $\mathrm{DAB}=$ 3,3diaminobenzidinetetrahydrochloride; DAPI $=4$ '-6Diamidino-2-phenylindole; NS = Non significant; IBC = Inflammatory Breast Carcinoma

\section{Competing interests}

The author(s) declare that they have no competing interests.

\section{Authors' contributions}

SSP and AJFM performed the study. SSP wrote the manuscript. CL participated in the immunohistochemistry method. NTM participated in the composition of the images. SSP and JC carried out the statistical analysis. CAR and FG participated in the design and coordination of the 
studies and contributed strongly to the revision of the manuscript. All the authors read and approved the final manuscript.

\section{Acknowledgements}

Supported by Portuguese agency " Fundação para a Ciência e a Tecnologia, Programa Operacional Ciência e Inovação 2010 (POCl 2010) do Quadro Comunitário de Apoio III" and Project grant no. POCl/CVT/57795/2004.

SSP acknowledges FCT for financial support (SFRH/BD/2 I693/2005).

\section{References}

I. Sorenmo K: Canine mammary gland tumors. Vet Clin Small Anim 2003, 33:573-596.

2. Owen LN: A comparative study of canine and human breast cancer. Invest Cell Pathol 1979, 2:257-275.

3. Kurzman ID, Gilbertson SR: Prognostic factors in canine mammary tumors. Seminars in Veterinary Medicine and Surgery (Small Animal) 1986, 1:25-32.

4. Kannagi R, Izawa M, Koike T, Miyazaki K, Kimura N: Carbohydratemediated cell adhesion in cancer metastasis and angiogenesis. Cancer Sci 2004, 95:377-384.

5. Hakomori S: Tumour malignancy defined by aberrant glycosylation and sphingo(glyco)lipid metabolism. Cancer Res 1996, 56:5309-53।8.

6. Borsig L, Wong R, Hynes RO, Varki NM, Varki A: Synergistic effects of $\mathrm{I}$ - and $\mathrm{p}$-selectin in facilitating tumour metastasis can involve non-mucin ligands and implicate leukocytes as enhancers of metastasis. Proc Natl Acad Sci 2002, 99:2 I 93-21 98.

7. Fukuda M: Possible roles of tumour-associated carbohydrate antigens. Cancer Res 1996, 56:2237-2244.

8. Numahata K, Satoh M, Handa K, Saito S, Ohyama C, Ito A, Takahashi T, Hoshi S, Orikasa S, Hakomori S: Sialosyl-lex expression defines invasive and metastatic properties of bladder carcinoma. Cancer 2002, 94:673-685.

9. Wang PH: Altered glycosylation in cancer: sialic acids and sialyltransferases. J Cancer Mol 2005, I:73-8I.

10. Hakomori S: Glycosylation defining cancer malignancy: new wine in an old bottle. Proc Natl Acad Sci 2002, 99:10231-10233.

II. Ono M, Hakomori S: Glycosylation defining cancer cell motility and invasiveness. Glycoconj J 2004, 20:71-78.

12. Dube DH, Bertozzi CR: Glycans in cancer and inflammation potential for therapeutics and diagnostics. Nature Reviews 2005, 4:477-488.

13. Monzavi-Karbassi B, Whitehead TL, Jousheghany F, Artaud C, Hennings L, Shaaf S, Slaughter A, Korourian S, Kelly T, Blaszczyk-Thurin $M$, Kieber-Emmons T: Deficiency in surface expression of eselectin ligand promotes lung colonization in a mouse model of breast cancer. Int J Cancer 2005, I 1 7:398-408.

14. Ugorski M, Laskowska A: Sialyl lewisa: a tumour-associated carbohydrate antigen involved in adhesion and metastatic potential of cancer cells. Acta Bioch Polon 2002, 49:303-3II.

15. Magnani JL: The discovery, biology, and drug development of sialyl le and sialyl le and lex. Arch Biochem Biophys 2004, 426: $|22-| 3 \mid$.

16. Varki A: Selectin ligands. Proc Natl Acad Sci USA 1994, 91:7390-7397.

17. Sawada R, Tsuboi S, Fukuda M: Differential E-selectin-dependent adhesion efficiency in sublines of a human colon cancer exhibiting distinct metastatic potentials. J Biol Chem 1994, 269: $1425-|43|$.

18. Kannagi R: Molecular mechanism for cancer-associated induction of sialyl Lewis $X$ and sialyl Lewis $A$ expression-The Warburg effect revisited. Glycoconjugate J 2004, 20:353-364.

19. Dabelsteen $\mathrm{E}$ : Cell surface carbohydrates as prognostic markers in human carcinomas. J Pathol 1996, 179:358-369.

20. Nakagoe T, Fukushima $K$, Itoyanagi N, Ikuta $Y$, Oka T, Nagayasu $T$, Ayabe H, Hara S, Ishikawa H, Minami H: Expression of abh/lewisrelated antigens as prognostic factors in patients with breast cancer. I Cancer Res Clin Oncol 2002, I 28:257-264.

21. Matsuura N, Narita T, Mitsuoka C, Kimura N, Kannagi R, Imai T, Funahashi H, Takagi H: Increased level of circulating adhesion molecules in the sera of breast cancer patients with distant metastases. Jpn J Clin Oncol 1997, 27:135-139.

22. Yu CJ, Shih JY, Lee YC, Shun CT, Yuan A, Yang PC: Sialyl lewis antigens: association with muc5ac protein and correlation with post-operative recurrence of non-small cell lung cancer. Lung Cancer 2005, 47:59-67.

23. Jeschke U, Mylonas I, Shabani N, Kunert-Keil C, Schindlbeck C, Gerber B, Friese K: Expression of sialyl lewis x, sialyl lewis a, e-cadherin and cathepsin-d in human breast cancer: immunohistochemical analysis in mammary carcinoma in situ, invasive carcinomas and their lymph node metastasis. Anticancer Res 2005, 25:1615-1622.

24. Jorgensen T, Berner A, Kaalhus O, Tveter KJ, Danielsen HE, Bryne M: Up-regulation of the oligosaccharide Sialyl Lewis ${ }^{x}$ : a new prognostic parameter in metastatic prostate cancer. Cancer Res 1995, 55:1817-1819.

25. Grabowski P, Mann B, Mansmann U, Lövin N, Foss HD, Berger G, Scherübl H, Riecken EO, Buhr HJ, Hanski C: Expression of SialylLe $^{x}$ antigen defined by Mab AM-3 is an independent prognostic marker in colorectal carcinoma patients. Int J Cancer 2000, 88:28I-286.

26. Ura H, Denno R, Hirata K, Yamaguchi K, Yasoshima T, Shishido T: Close correlation between increased sialyl-lewis $\mathrm{x}$ expression and metastasis in human gastric carcinoma. World J Surg 1997, 21:773-776.

27. Amado M, Carneiro F, Seixas M, Clausen H, Sobrinho-Simões $M$ : Dimeric Sialyl-Le ${ }^{x}$ expression in gastric carcinoma correlates with venous invasion and poor outcome. Gastroenterology 1998, I | 4:462-470.

28. Futamura N, Nakamura S, Tatematsu M, Yamamura Y, Kannagi R, Hirose H: Clinicopathologic significance of sialyl Lex expression in advanced gastric carcinoma. Br J Cancer 2000, 83: $168 \mid-1687$.

29. Nakagawa T, Uyama R, Ohashi E, Takahashi T, Hong SH, Mochizuki $M$, Matsunaga S, Nishimura R, Sasaki N: The expression of sialyl lewis $\mathbf{x}$ in canine and feline mammary gland tumors. J Vet Med Sci 2002, 64:949-952.

30. Alpaugh ML, Tomlinson JS, Kasraeian S, Barsky SH: Cooperative role of e-cadherin and sialyl-lewis $\mathrm{x} / \mathrm{a}$-deficient mucl in the passive dissemination of tumour emboli in inflammatory breast carcinoma. Oncogene 2002, 21:363I-3643.

31. Alpaugh ML, Tomlinson JS, Ye Y, Barsky SH: Relationship of sialyllewis ${ }^{\mathrm{x} / a}$ underexpression and e-cadherin overexpression in the lymphovascular embolus of inflammatory breast carcinoma. Am J Pathol 2002, 161:619-628.

32. Alpaugh ML, Barsky SH: Reversible model of spheroid formation allows for high efficiency of gene delivery ex vivo and accurate gene assessment in vivo. Hum Gene Ther 2002, 13:1245-1258.

33. Matos AJF, Lopes C, Carvalheira J, Santos M, Rutteman GR, Gärtner $F$ : E-cadherin expression in canine malignant mammary tumours: relationship to other clinico-pathological variables. J Comp Path 2006, 134:182-189.

34. Misdorp W, Else RW, Hellmén E, Lipscomb TP: Histological classification of the mammary tumours of the dog and the cat. In World Health Organization International Histological Classification of Tumours of Domestic Animals Edited by: Shulman Fl. Armed Forces Institute of Pathology, Washington DC; 1999:16-29.

35. Hsu SM, Faine L, Fanger H: A comparative study of the peroxidase-antiperoxidase method and the avidin-biotin complex method for studying polypeptide hormones with radioimmunoassay antibodies. Am J Clin Pathol I98I, 75:734-738.

36. Fukushi $Y$, Nudelman E, Levery SB, Hakomori S, Rauvala H: Novel fucolipids accumulating in human adenocarcinoma: III a hybridoma antibody (FH6) defining a human cancer-associated difucoganglioside $\left(\mathrm{VI}^{3} \mathrm{NeuAcV}^{3} \mathrm{III}^{3} \mathrm{Fuc}_{2} \mathrm{nLc}_{6}\right)$ ). J Biol Chem 1984, 259:105II-10517.

37. SAS Institute Inc: SAS/STAT ${ }^{\circledR}$ User's Guide, Version 6. Volume I. Fourth edition. Cary, NC: SAS Institute Inc; 1989:943.

38. Kannagi R: Carbohydrate-mediated cell adhesion involved in hematogenous metastasis of cancer. Glycoconj J 1997, 14:577-584.

39. Kurahara S, Shinohara M, lkebe T, Nakamura S, Hiraki A, Sasaki M, Beppu M, Shirasuna K: Immunohistochemical study of sialyl le ${ }^{a}$ and sialyl le $e^{x}$ antigen in oral squamous cell carcinoma: the 
association of sialyl le $\mathrm{e}^{\mathrm{a}}$ expression with the metastatic potential. Head Neck 1999, 21:330-337.

40. Farmer RW, Richtsmeier WJ, Scher RL: Identification of sialyl lewis- $x$ in squamous cell carcinoma of head and neck. Head Neck 1998, 20:726-73I.

4I. Nakagawa T, Watanabe M, Ohashi E, Uyama R, Takauji S, Mochizuki $M$, Nishimura R, Ogawa H, Sugano S, Sasaki N: Cyclopedic protein expression analysis of cultured canine mammary gland adenocarcinoma cells from six tumours. Res Vet Sci 2006, 80:317-323.

42. Peña L, Perez-Alenza D, Rodriguez-Bertos A, Nieto A: Canine inflammatory mammary carcinoma: histopathology, immunohistochemistry and clinical implications of $2 \mathrm{I}$ cases. Breast Cancer Res Treat 2003, 78: 141-148.

43. Benjamin SA, Lee AC, Saunders W]: Classification and behaviour of canine mammary epithelial neoplasms based on life-span observations in beagles. Vet Pathol 1999, 36:423-436.

44. Bostock DE: The prognosis following the surgical excision of canine mammary neoplasms. Europ J Cancer 1975, I I:389-396.

45. Parham DM, Hagen N, Brown RA: Simplified method of grading primary carcinomas of the breast. I Clin Pathol 1992, 45:517-520.

46. Gilchrist KW, Gray R, Fowble B, Tormey DC, Taylor SG: Tumor necrosis is a prognostic predictor for early recurrence and death in lymph node-positive cancer: a 10 -year follow-up study of 728 Eastern Cooperative Oncology Group patients. J Clin Oncol 1993, I I:1929-1935.

47. Carlomagno C, Perrone F, Lauria R, de Laurentiis M, Gallo C, Morabito A, Pettinato G, Panico L, bellelli T, Apicella A: Prognostic significance of necrosis, elastosis, fibrosis and inflammatory cell reaction in operable breast cancer. Oncology 1995, 52:272-277.

48. Liotta LA, Stetler-Stevenson WG, Steeg PS: Cancer invasion and metastasis: positive and negative regulatory elements. Cancer Invest |99|, 9:543-55|.

49. Brunetti B, Sarli G, Preziosi R, Monari I, Benazzi C: E-Cadherin expression in canine mammary carcinomas with regional lymph node metastases. J Vet Med 2003, 50:496-500.

50. Birchmeier W, Behrens J: Cadherin expression in carcinomas: role in the formation of cell junctions and the prevention of invasiveness. Biochim Biophys Acta 1994, I 198: I I-26.

\section{Pre-publication history}

The pre-publication history for this paper can be accessed here:

http://www.biomedcentral.com/1471-2407/7/124/pre $\underline{\mathrm{pub}}$
Publish with Biomed Central and every scientist can read your work free of charge

"BioMed Central will be the most significant development for disseminating the results of biomedical research in our lifetime. "

Sir Paul Nurse, Cancer Research UK

Your research papers will be:

- available free of charge to the entire biomedical community

- peer reviewed and published immediately upon acceptance

- cited in PubMed and archived on PubMed Central

- yours - you keep the copyright
BioMedcentral 